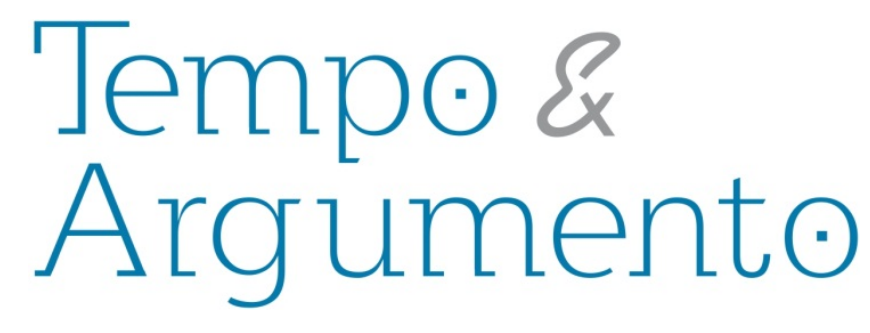

\title{
Ditadura e democracia: entre memórias e história
}

\section{REIS FILHO, Daniel Aarão. Ditadura e democracia no Brasil: do golpe de 1964 à Constituição de 1988. Rio de Janeiro: Zahar, 2014.}

Autores:

\section{Luisa Rita Cardoso}

Mestranda do Programa de Pós-Graduação em História da Universidade do Estado de Santa Catarina. louisarita@gmail.com

\section{Hudson Campos Neves}

Mestrando do Programa de Pós-Graduação em História da Universidade do Estado de Santa Catarina. hudsoncn.historia@gmail.com

\footnotetext{
Para citar esta resenha:

CARDOSO, Luisa Rita; NEVES, Hudson Campos. Ditadura e democracia: entre memórias e história. Revista Tempo e Argumento, Florianópolis, v. 6, n.11, p. 461-466, jan./abr. 2014.
} 
Publicado pela editora Zahar quando o golpe civil-militar contra o governo constitucional de João Goulart completa 50 anos, o livro Ditadura e democracia no Brasil: do golpe de 1964 à Constituição de 1988, de Daniel Aarão Reis Filho, aborda o clima de tensão e polarização que levou ao golpe, a ditadura militar que é então tramada e a transição desta para a democracia. O historiador percorre, numa narrativa fluida, o governo de Jânio Quadros e as tensões que envolveram, a partir de sua renúncia, a posse de Jango e os principais processos históricos relacionados ao golpe: a consolidação do regime, seu apogeu e enfraquecimento com a gradativa perda de apoio de setores da sociedade que outrora lhe deram sustentação. A obra trata ainda de fatores que fizeram parte do lento processo de abertura política, que, segundo o autor, só se consolidou com a Constituição de 1988.

Professor titular de História Contemporânea da Universidade Federal Fluminense (UFF) e autor de importantes trabalhos como A revolução faltou ao encontro: os comunistas no Brasil, lançado em 1990 e Ditadura Militar, esquerdas e sociedade, de 2000, Aarão Reis, numa linguagem não academicista e com poucas notas explicativas, divide o livro em sete capítulos e uma reflexão final sobre ditadura e democracia no Brasil. Diante da impossibilidade de abordar todos os elementos discutidos nas 191 páginas de Ditadura e democracia no Brasil, optamos por, nesta resenha, tratar daqueles que a nosso ver mais contribuem para a construção de um olhar crítico sobre o período.

O capítulo de abertura do livro, Ditadura no Brasil: uma incômoda e contraditória memória, traz, já no título, a problemática da memória em torno do período. Parece-nos que a decisão de tratar primeiramente desta funciona como um alerta: é preciso que o leitor esteja atento às verdades mais recorrentes sobre o tema e disposto a entendê-las como construções sociais, para o autor mais ligadas à memória do que à empiria dos estudos históricos. Assim é problematizada a resistência à ditadura. Aarão Reis aponta que "versões memoriais apaziguadoras" (REIS FILHO, 2014, p. 8) foram elaboradas nos anos 1980 em nome da conciliação nacional, deixando de lado o debate acerca das bases sociais que sustentaram o regime. Diante do processo que levaria ao fim da ditadura, a sociedade brasileira apegou-se a valores democráticos, negando ter colaborado, apoiado ou até mesmo sido indiferente frente os acontecimentos do período ditatorial. Conforme o autor, "a ditadura no Brasil, até pelo 
longo período que durou, foi uma construção histórica. Impossível compreendê-la sem trazer à tona suas bases políticas e sociais - múltiplas e diferenciadas" (REIS FILHO, 2014, p. 128).

Desta forma, a formulação mais amplamente aceita passa a ser a de que "a sociedade fora silenciada pela força e pelo medo da repressão. Mas resistira” (REIS FILHO, 2014, p. 8). Ao longo do livro, as ambiguidades e ambivalências em torno da resistência aparecem em diferentes âmbitos: o dos intelectuais, da música, do cinema e, com mais ênfase, o da luta armada. Como o próprio historiador, destacaremos aqui as disputas em torno do último. Utilizando-se do termo esquerda revolucionária, Aarão Reis é enfático ao apontar as motivações da luta armada como partidária não só da superação da ditadura, mas do capitalismo no Brasil. Assim, tratar as organizações que pegaram em armas como "uma espécie de braço armado" (REIS FILHO, 2014, p. 133) da resistência democrática seria mais uma vitória das forças conciliadoras que, ao negar os conflitos de classe, criavam melhores condições para a reinstalação da democracia. É isso que o autor chama de o primeiro deslocamento de sentido promovido por aqueles que, em fins dos anos 1970, reuniam forças em torno de uma anistia ampla.

Outro deslocamento de sentido apontado emerge das forças de direita que, sustentando ter havido uma guerra revolucionária, entendiam ambos os lados como culpados que deveriam, portanto, ser anistiados. É o raciocínio que na Argentina, ao tratar também da última ditadura, sistematizou-se sob o nome de tese dos dois demônios. Haveria ainda um terceiro deslocamento de sentido, mais geral, em que a sociedade, passando a se perceber como democrática, coloca-se contra a ditadura, entendendo a mesma como um corpo estranho, que nunca encontrara apoio civil. Dessa forma, "redesenhou-se o quadro das relações complexas entre sociedade e ditadura, que apareceu como permanentemente hostilizada pelas gentes" (REIS FILHO, 2014, p. 135).

A ideia de que o golpe foi inevitável, como ainda hoje se menciona, inclusive na grande mídia nacional ${ }^{1}$, é questionada pelo autor, que articula o contexto nacional daquele período

1 Ver editorial do periódico "Folha de São Paulo", publicado no dia 03 de março de 2014. Disponível em: <http://www1.folha.uol.com.br/opiniao/2014/03/1433004-editorial-1964.shtml> Acessado em: 15 de maio de 2014. 
com processos mais amplos, em escala global, que teriam provocado a atitude golpista. Assim, afirma que

o nacionalismo e o reformismo radicais assustavam, em virtude do exemplo da Revolução Cubana, cujo caráter nacional-democrático cedo se transmudara, desde 1961, numa proclamada revolução socialista. Outros movimentos de libertação nacional em curso aproximavam nacionalismo e socialismo, como na China, no mundo árabe (Argélia, Síria e Iraque), no Vietnã, e mesmo entre os pequenos grupos revolucionários que despontavam então nas ex-colônias portuguesas. (REIS FILHO, 2014, p. 47)

Aarão também destaca a relativa autonomia das forças golpistas e assinala que é um equívoco superestimar a participação do governo dos Estados Unidos neste processo. Ou seja: Washington apoiou o golpe, mas o mesmo não ocorreu apenas porque havia uma esquadra norte-americana a caminho do litoral brasileiro.

É lugar comum compreender a duração da última ditadura militar ocorrida no Brasil como sendo de um período de 21 anos, tendo iniciado com o golpe civil-militar, em abril de 1964, e terminado com a eleição, ainda que indireta, de um civil para o cargo de Presidente da República, em 1985. Aarão contesta tal leitura. Nesta obra, defende a tese de que com a revogação dos Atos Institucionais, em 1979, tem início o período de transição democrática, que, por sua vez, termina com a aprovação da nova Constituição, em 1988. Para ele:

o País deixou de ser regido por uma ditadura - predomínio de um estado de exceção, quando prevalece a vontade, arbitrária, dos governantes, que podem fazer e desfazer leis - sem adotar de imediato, através de uma Assembleia eleita, uma Constituição democrática. Em outras palavras: no período de transição já não havia ditadura, mas ainda não existia uma democracia. (REIS FILHO, 2014, p. 125)

Assim, 1979 marcaria o fim da ditadura militar e o início de um período de estado de direito autoritário, findo em 1988. Aarão Reis afirma que houve uma "ampla coligação de interesses e vontades" (REIS FILHO, 2014, p. 127) para que se consolidasse a ideia de que a ditadura encerrou com a posse de José Sarney e aponta que há, por trás disso, uma "ideiaforça" que não tem respaldo nas evidências, a saber, a "de que a ditadura fora obra apenas dos militares, reconstruídos como bodes expiatórios" (REIS FILHO, 2014, p. 127) e responsáveis únicos pelo fim do governo constitucional. Só neste sentido a eleição de um civil seria o momento da mudança, quando o poder, finalmente, sairia das mãos dos militares. 
No tocante às questões econômicas, Aarão Reis elabora longas explanações, utilizando-se de dados do período e de revisão bibliográfica. Uma discussão, no entanto, merece aqui destaque por seu caráter inovador, a saber, aquilo que o autor chama de cultura política nacional-estatista ${ }^{2}$ (ou cultura política do nacional-estatismo). Inaugurada pelo Estado Novo e embasada no nacional-estatismo, que ambicionava construir uma única identidade nacional e entendia ser "o Estado o melhor instrumento histórico para articular a vontade nacional na direção de um processo autônomo de modernização" (REIS FILHO, 2014, p. 19), a cultura política nacional-estatista teria sido retomada por Costa e Silva e aprofundada por Médici. Se Castello Branco havia tentado minimizar o Estado perante a economia com seu “programa liberal-internacionalista” (REIS FILHO, 2014, p. 80), que alinhava o Brasil com os Estados Unidos e buscava atrair capital privado, seus sucessores retomam as bases Estadonovistas e "o Estado voltava a incentivar, regular, financiar e proteger, intervindo ativamente nos mais variados setores econômicos" (REIS FILHO, 2014, p. 80). Tal cultura política não é, para o autor, uma exclusividade de ditadores - de Vargas aos militares - mas permeia diferentes setores da sociedade brasileira, à direita e à esquerda, estendendo-se até nossos dias.

Daniel Aarão Reis, por fim, alerta-nos para uma questão fundamental para o tempo presente: "não há como se libertar da ditadura sem pensar nela” (REIS FILHO, 2014, p. 171), fazendo, desta obra, um esforço democrático de um pensador que acredita que a melhor defesa da democracia é o pensamento crítico, “à maneira de um antídoto às tentações autoritárias" (REIS FILHO, 2014, p. 171).

2 A ideia é mais amplamente discutida em: AARÃo Reis, Daniel. A ditadura faz cinquenta anos: história e cultura política nacional-estatista. In: AARÃO REIS, Daniel; RIDENTI, Marcelo; MOTTA, Rodrigo Patto Sá. A ditadura que mudou o Brasil: 50 anos do golpe de 1964. 2014. p. 11-29. 
Recebido em: 01/04/2014 Aprovado em: 20/04/2014

Universidade do Estado de Santa Catarina - UDESC Programa de Pós-Graduação em História - PPGH Revista Tempo e Argumento Volume 06 - Número 11 - Ano 2014 tempoeargumento@gmail.com 